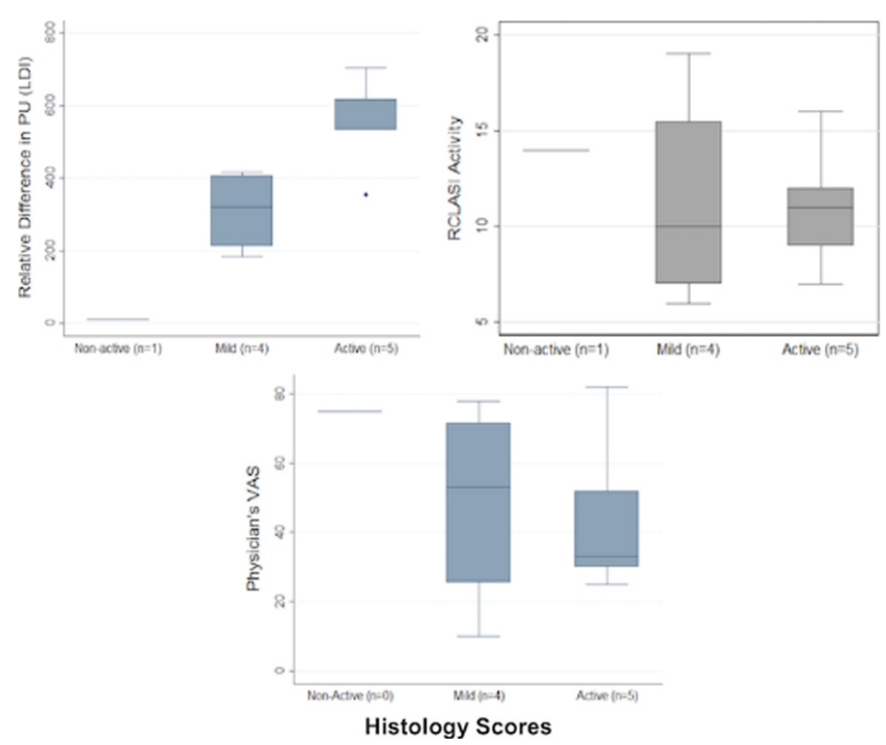

Disclosure of Interest: None declared

DOI: 10.1136/annrheumdis-2017-eular.6784

\section{SAT0648 ULTRASOUND FINDINGS IN SYMPTOMATIC AND ASYMPTOMATIC JOINTS IN PATIENTS WITH GOUT}

M.M. Basaric, G. Radunovic, N. Damjanov, M. Radak Perovic. Institut of rheumatology, Belgrade, Serbia

Objectives: To determine sensitivity and specificity of ultrasound (US) findings for gout: "double contours" (DC) and hyperechogenic aggregates (HAGs) of symptomatic and asymptomatic joints in patients with gout.

Methods: This prospective study included 69 persons (34 patients with primary gout and 35 healthy subjects). Including criteria for patients with gout were: age $\geq 18$ years; diagnosis of primary gout; absence of acute gout attacks during the study tests; the absence of any other inflammatory and infectious joint disease, and secondary gout. The research included: demography and medical history. Physical and US examination covered following structures: 138 radiocarpal joint, 276 patellar and triceps tendon and 414 articular cartilages (first metatarsal, talar and femoral condyle).

Results: Both groups were compatible for age and gender. In the gout group 124 $(30 \%)$ symptomatic and $284(70 \%)$ asymptomatic joints were found and in healty group all joints was asymptomatic. The sensitivity of the DC for symptomatic joint was 56 to $84 \%$ and specificity also was very high 91 to $94 \%$ as well as positive and negative predictive value (69-86\% and $38-71 \%)$. Sensitivity of DC finding for the asymptomatic joints was 42 to $73 \%$ and specificity was 91 to $94 \%$, with also high positive and negative predictive value (69-89\% and $44-62 \%)$. The specificity of the HAGs for both symptomatic and asymptomatic joints was very high $99 \%$ but sensitivity of HAGs symptomatic structures was moderate (41 do $56 \%$ ), while its sensitivity for asymptomatic structures was low (18 to $34 \%$ ), table 1 .

Table 1

\begin{tabular}{lcccccc}
\hline Structure & & Sensitivity $(\%)$ & Specificity $(\%)$ & "Cut-off" & PPV (\%) & NPV (\%) \\
\hline Symptomatic & DC & $56-84$ & $91-94$ & 0.50 & $69-86$ & $38-71$ \\
& HAGs & $41-56$ & $98-99$ & 0.50 & $69-89$ & $44-62$ \\
Asymptomatic & DC & $42-73$ & $91-94$ & 0.50 & $58-86$ & $38-71$ \\
& HAGs & $18-34$ & $98-99$ & 0.50 & $49-75$ & $31-60$ \\
\hline
\end{tabular}

DC - "double contours"; HAGs - hyperechogenic aggregates; PPV - positive predictive values; NPV - negative predictive values.

Conclusions: Ultrasound examination of symptomatic and asymptomatic joints in patients with gout equally observed structural changes characteristic of gout. The finding of "double contours" in the symptomatic and asymptomatic joints has a very high sensitivity and specificity. Consequently, future research should be focused on the ultrasound examination of asymptomatic joints in patients with gout.

Disclosure of Interest: None declared

DOI: 10.1136/annrheumdis-2017-eular.4199

\section{SAT0649 CHANGES IN CARTILAGE QUALITY (DGEMRIC) FOLLOWING KNEE JOINT DISTRACTION OR HIGH TIBIAL OSTEOTOMY: A TWO-YEAR FOLLOW-UP}

N. Besselink $^{1}$, S. Mastbergen ${ }^{1}$, K. Vincken ${ }^{2}$, L. Bartels ${ }^{2}$, A. Concepcion ${ }^{1}$, A.K. Marijnissen ${ }^{1}$, F. Lafeber ${ }^{1} .{ }^{1}$ Rheumatology and Clinical Immunology; ${ }^{2}$ Image Sciences Institute, University Medical Centre Utrecht, Utrecht, Netherlands

Background: Since abnormal loading can cause onset and progression of OA, unloading the affected compartment of an osteoarthritic knee, should slow down OA progression, or even enable joint repair. High tibial osteotomy (HTO) is a well-known unloading approach for treating unilateral compartment osteoarthritis (OA) with mechanical axis deviation. Transient unloading using knee joint distraction (KJD) has demonstrated a progressive decrease in pain, normalization of function, and an increase in cartilage thickness ${ }^{1}$. Although both treatments show indications of joint repair, there is limited information about the actual quality of the regenerated tissue.

Objectives: To evaluate the change in quality of the repaired cartilaginous tissue using dGEMRIC after KJD or HTO treatment.

Methods: 40 patients ( 20 with KJD, and 20 with HTO), treated for medial tibiofemoral $\mathrm{OA}$, are included in this study. Radiographic changes, clinical changes, and changes in cartilage quality are evaluated after one and two years follow-up. Joint space width (JSW) is evaluated on weight-bearing radiographs. Clinical improvement is evaluated by Western Ontario and McMaster Universities Osteoarthritis Index (WOMAC) and Visual Analogue Scale (VAS) pain score. In order to evaluate the quality of the (newly formed) cartilaginous tissue, quantitative $\mathrm{MRI}$ analysis, in the form of Delayed gadolinium enhance Magnetic Resonance Imaging of cartilage (dGEMRIC) is performed.

Results: A significantly increased medial $(\Delta 1.15 \mathrm{~mm}, \mathrm{p}<0.000)$, minimal $(\Delta 0.93$ $\mathrm{mm}, \mathrm{p}<0.000)$ and mean $(\Delta 0.79 \mathrm{~mm}, \mathrm{p}=0.003) \mathrm{JSW}$ one year after KJD, sustaining up until 2 years, was demonstrated (medial $(\Delta 0.99 \mathrm{~mm}, \mathrm{p}=0.002$ ), minimal $(\Delta 1.04 \mathrm{~mm}, \mathrm{p}<0.000)$, mean JSW $(\Delta 0.68 \mathrm{~mm}, \mathrm{p}=0.027))$. Similarly, medial $(\Delta 0.49$ $\mathrm{mm}, \mathrm{p}=0.017)$ and minimal $(\Delta 0.32 \mathrm{~mm}, \mathrm{p}=0.023) \mathrm{JSW}$ were significantly increased one year after HTO, sustaining up until 2 years (medial: $\Delta 1.03 \mathrm{~mm}, \mathrm{p}<0.000$, minimal: $\Delta 0.72 \mathrm{~mm}, \mathrm{p}=0.015)$, after which mean JSW $(\Delta 0.46 \mathrm{~mm}, \mathrm{p}=0.030)$ is also significantly increased. Both interventions led to clinical improvement, observed as an increase in WOMAC after one year (KJD: $\triangle 36.89, p<0.000, H T O$ : $\Delta 33.74, p<0.000$ ) and two years (KJD: $\Delta 32.52, p<0.000, H T O: \Delta 24.19, p=0.002$ ), and a decrease in VAS Pain, after one year (KJD: $\Delta-30.79, \mathrm{p}=0.001$, HTO: $\Delta$ $41.89, p<0.000$ ) and two years (KJD: $\Delta-30.50, p=0.004$, HTO: $\Delta-34.64, p<0.000$ ). However, no statistically significant changes in cartilage quality were found after KJD or HTO, not in the medial and lateral compartments of the tibiofemoral joint, nor in the separate ROls (see figure 1).
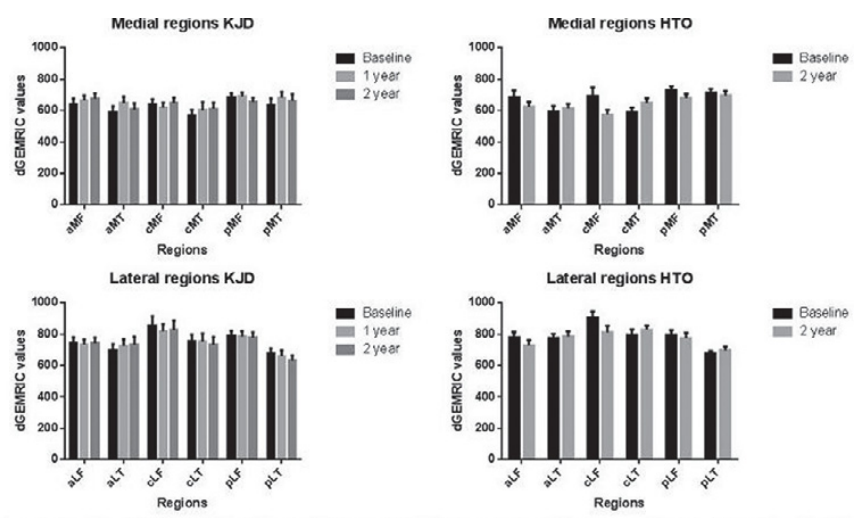

Figure 1: Aver

Conclusions: Treatment of medial compartmental OA by either HTO or KJD leads to alleviation of pain and recovery of function, achieved one year after either intervention, and maintained for another year. Within the first year after treatment, KJD shows a statistically significantly higher increase in WOMAC as compared to HTO. Both treatments led to a statistically significant increase in JSW after one and two years, postponing the natural osteoarthritis progression rate. No statistically significant change in the quality of newly formed cartilaginous tissue could be detected by dGEMRIC.

References:

[1] van der Woude et al. Knee joint distraction compared with high tibial osteotomy. 2016. Knee Surgery,Sports Traumatology,Arthroscopy,1-11.

Disclosure of Interest: None declared

DOI: 10.1136/annrheumdis-2017-eular.3400

\section{SAT0650 [18F]FLUORO-PEG-FOLATE PET: A NOVEL IMAGING TECHNIQUE TO VISUALIZE RHEUMATOID ARTHRITIS}

N. Verweij ${ }^{1}$, S. Bruijnen ${ }^{1}$, Y. Gent ${ }^{1}$, M. Huisman ${ }^{2}$, G. Jansen ${ }^{1}$, C. Molthoff ${ }^{2}$, Q. Chen ${ }^{3}$, P. Low ${ }^{3}$, A. Windhorst ${ }^{2}$, A. Lammertsma ${ }^{2}$, O. Hoekstra ${ }^{2}$, A. Voskuyl ${ }^{1}$, C. van der Laken $1 .{ }^{1}$ Dept. of Rheumatology, Amsterdam Rheumatology and Immunology Center - location VU University Medical Center; ${ }^{2}$ Dept. of Radiology \& Nuclear Medicine, VU University Medical Center, Amsterdam, Netherlands;

${ }^{3}$ Dept. of Chemistry, Purdue University, West Lafayette, United States

Background: Imaging arthritis activity in rheumatoid arthritis (RA) patients using PET macrophage tracers holds promise for both early diagnostics and monitoring response to therapy $(1,2)$. Previously, $(R)-\left[{ }^{11} \mathrm{C}\right] \mathrm{PK} 11195$ has been used, but this macrophage tracer is limited due to high background uptake, especially in bone and bone marrow. Recently, a novel macrophage tracer, $\left[{ }^{18} \mathrm{~F}\right]$ fluoro-PEG-folate, 